\title{
Diverse Fusarium solani isolates colonise agricultural environments in Ethiopia
}

\author{
M. Bogale • E.T. Steenkamp • M.J. Wingfield • \\ B.D. Wingfield
}

Received: 12 June 2008 / Accepted: 11 December 2008 /Published online: 14 January 2009

(C) KNPV 2009

\begin{abstract}
Fusarium solani is a fungal pathogen that infects many different genera of plants. It represents one of the two Fusarium spp. commonly isolated from agricultural soils and plant tissues in Ethiopia. To determine the diversity of $F$. solani in Ethiopia, we studied 43 isolates using Amplified Fragment Length Polymorphism (AFLP) and nucleotide sequences of the Translation Elongation Factor $1 \alpha($ TEF- $1 \alpha)$ and $\beta$-tubulin genes. TEF- $1 \alpha$ sequences from GenBank, representing previously described species and clades of the F. solani-Haematonectria haematococca complex, were also included for comparative purposes.
\end{abstract}

\footnotetext{
M. Bogale $(\square) \cdot B$. Wingfield

Department of Genetics,

Forestry and Agricultural Biotechnology Institute,

University of Pretoria,

Pretoria, South Africa

e-mail: mesfin.bogale@FABI.UP.AC.ZA

B. Wingfield

e-mail: brenda.wingfield@fabi.up.ac.za

E. Steenkamp $\cdot$ M. Wingfield

Department of Microbiology and Plant Pathology, Forestry

and Agricultural Biotechnology Institute,

University of Pretoria,

Pretoria, South Africa

E. Steenkamp

e-mail: emma.steenkamp@fabi.up.ac.za

M. Wingfield

e-mail: mike.wingfield@fabi.up.ac.za
}

Phylogenetic analyses of the TEF- $1 \alpha$ data separated the isolates into three groups corresponding with the three previously described clades (Clades 1-3) for this fungus. The Ethiopian isolates aggregated into one group corresponding to Clade 3. TEF- $1 \alpha, \beta$-tubulin and AFLPs further separated the Ethiopian isolates into a number of clusters and apparently novel phylogenetic lineages. Although the biological and ecological significance of these lineages and clusters is unclear, our data show that the Ethiopian agricultural environment is rich in species and lineages of the F. solani-H. haematococca complex.

Keywords AFLP. $\beta$-tubulin $\cdot$ Ethiopia

Fusarium solani $\cdot$ TEF- $1 \alpha$

\section{Introduction}

Fusarium solani (teleomorph Haematonectria haematococca; Rossman et al. 1999; syn. Nectria haematococca) is a widely distributed soil-borne fungus pathogenic to at least 111 plant species spanning 87 genera (Kolattukudy and Gamble 1995). It causes wilt and rot diseases on a wide variety of crops including Cucurbita spp. (Hawthorne et al. 1992), Pisum sativum (Van Etten 1978) and Phaseolus vulgaris (Li et al. 1995).

Fusarium solani is distinguished from other Fusarium spp. based on a number of morphological features (Leslie and Summerell 2006). The most important of 
these are the conditions under which it grows in culture (Matuo and Snyder 1973), the appearance of its chlamydospores, as well as long monophialides and macroconidia, although the macroconidia have been shown to vary in size with geographical origin (Burgess et al. 1994). Within this species, isolates are typically grouped based on pathogenicity, sexual compatibility and DNA-sequence comparisons. Based on pathogenicity to specific plant hosts, $F$. solani has been divided into ten formae speciales (Matuo and Snyder 1973), of which forma specialis cucurbitae includes two distinct races (Toussoun and Snyder 1961). These two races and five of the known formae speciales have been shown to represent distinct biological species designated as mating populations (MPs) I-VII, with $H$. haematococca as the teleomorph (Matuo and Snyder 1973; Van Etten and Kistler 1988). However, application of pathogenicity and sexual compatibility tests for diagnostic purposes is impractical, time-consuming and often inconclusive. This is because these assays are affected by factors such as the environment and genetic make-up of the host species, in the case of pathogenicity test, and fertility of the interacting individuals, in the case of sexual compatibility tests (Leslie and Summerell 2006). Furthermore, only positive mating tests provide guaranteed identifications (Matuo and Snyder 1973), and loss of virulence can result in lack of repeatability of experiments (Windels 1991).

Various DNA-based methods have been employed to identify or characterise isolates of $F$. solani (e.g., O'Donnell 2000; Godoy et al. 2004; Zhang et al. 2006). Of these, phylogenetic analysis of nucleotide sequences for multiple loci appears to be the most informative, and has been used to show that F. solani represents a species complex (O'Donnell 2000) consisting of over 26 discrete phylogenetic species, seven of which correspond to MPs I-VII (O’Donnell 2000; Aoki et al. 2003, 2005). Another very informative DNA-based method for resolving inter- and intra-specific relationships is Amplified Fragment Length Polymorphism (AFLP, Vos et al. 1995). Although this technique has not been used previously for F. solani, we successfully employed it to study the phylogeny of Fusarium oxysporum isolates (Bogale et al. 2006). A major advantage offered by the AFLP technique is that it allows genome-wide sampling rather than considering specific regions as is the case with nucleotide sequences (Majer et al. 1996).
The objective of this study was to assess the phylogenetic relationships of $F$. solani isolates obtained from agricultural soils and plant tissues in Ethiopia using AFLP and DNA sequence analyses. Furthermore, we compared the Ethiopian collection with isolates representing previously characterised species and/or groups in the F. solani-H. haematococca species complex.

\section{Materials and methods}

Sample collection and isolation of $F$. solani strains

Soil samples were collected in September 2000 from 23 farms previously planted to different cereals and pulses (Table 1). Four composite samples were collected from an area of 4-6 $\mathrm{m}^{2}$ at a depth of 3$15 \mathrm{~cm}$ along the diagonals of each farm visited. Wheat and barley samples were collected in August 2001 from three different farms in the Shoa region (Table 1). From each farm, samples were collected at five points along the diagonals of the field, where 10 15 plants close to harvesting were sampled from an area of $\sim 4 \mathrm{~m}^{2}$ at each point. Stem samples were collected from plants cut close to the ground. Banana root samples were also collected in August 2001 from 100 Cavendish plants grown on a commercial farm at Arbaminch (Table 1). Sampled banana plants were at least $10 \mathrm{~m}$ apart from each other. Five to eight root pieces, each $\sim 5 \mathrm{~cm}$ in length, were taken from the selected banana plants at $5-10 \mathrm{~cm}$ depth from the surface of the ground.

Fusarium strains were isolated from air-dried soil samples following the dilution plate method (Nelson et al. 1983). Plant tissues (wheat stems, barley stems and banana roots) were surface-sterilised using $\mathrm{NaOCl}(1.5 \% v / v)$ before fungal isolation. Strains were first isolated from these samples on a Fusariumselective pentachloronitrobenzene (PCNB) medium (Nash and Snyder 1962). Individual colonies were then transferred to MEA medium $(2 \% \quad w / v$ malt extract, $1.5 \% \mathrm{w} / \mathrm{v}$ agar), and incubated for 10 15 days at $25^{\circ} \mathrm{C}$ in the dark. Spores were gently washed from the surface of the cultures, diluted with sterile distilled water, and spread on a sterile water agar medium $(1.5 \% \mathrm{w} / \mathrm{v})$. After incubation at $25^{\circ} \mathrm{C}$ for 16-24 h under fluorescent light, single germinating spores were identified using a stereomicroscope, aseptically transferred to MEA plates and incubated 
Table 1 Strain numbers, source and geographic origin of the F. solani isolates used in this study

\begin{tabular}{|c|c|c|c|}
\hline \multirow[t]{2}{*}{ Strain number } & \multirow{2}{*}{$\begin{array}{l}\text { Source } \\
\text { (host/substrate) }^{\mathrm{a}}\end{array}$} & \multicolumn{2}{|l|}{ Location $^{\mathrm{b}}$} \\
\hline & & Region & Lat./Long. \\
\hline $\begin{array}{l}\text { FCC 3631, FCC3681, FCC3734, FCC3782, FCC3789, } \\
\text { FCC 3794, FCC3809, FCC4359, FCC4632 }\end{array}$ & Banana root & Arbaminch & $06.04 / 37.55$ \\
\hline FCC 3749 & Barley stem & North Shoa & $09.85 / 39.76$ \\
\hline FCC2926, FCC3723, FCC4636 & Soil (Barley) & Bale & $07.86 / 39.63$ \\
\hline FCC2934 & Soil (Barley) & West Shoa & $09.07 / 38.50$ \\
\hline FCC3735 & Soil (Barley) & Gondar & $12.12 / 37.78$ \\
\hline FCC3810 & Soil (Barley) & Sidamo & $05.88 / 38.98$ \\
\hline FCC3695 & Soil (Maize) & East Shoa & $08.60 / 39.12$ \\
\hline FCC3814 & Soil (Maize) & Wollo & $11.08 / 39.74$ \\
\hline FCC3820, FCC4633 & Soil (Maize) & Zeway & $07.93 / 38.71$ \\
\hline FCC3612 & Soil (Pulses) & Gondar & $12.12 / 37.78$ \\
\hline FCC3639 & Soil (Pulses) & Bale & $07.08 / 38.70$ \\
\hline FCC3689 & Soil (Pulses) & Gondar & $11.73 / 38.47$ \\
\hline FCC3649, FCC3650 & Soil (Sorghum) & Wollo & $12.50 / 39.53$ \\
\hline FCC4634 & Soil (Sorghum) & Gondar & $11.86 / 38.01$ \\
\hline FCC2930 & Soil $(t e f)$ & Gondar & $11.60 / 37.40$ \\
\hline FCC3613 & Soil (tef) & Sidamo & $05.63 / 38.23$ \\
\hline FCC3632, FCC3686 & Soil (tef) & Gojjam & $10.69 / 37.26$ \\
\hline FCC3661 & Soil (tef) & Gondar & $11.92 / 37.70$ \\
\hline FCC3736 & Soil (tef) & Wollo & $10.72 / 39.87$ \\
\hline FCC3776 & Soil (tef) & Shoa & $08.66 / 38.21$ \\
\hline FCC 3815, FCC3816, FCC3623 & Soil (tef) & East Shoa & $08.55 / 39.27$ \\
\hline FCC4631 & Soil (tef) & Wollega & $09.09 / 36.53$ \\
\hline FCC3625 & Soil (Wheat) & Bale & $06.97 / 39.18$ \\
\hline FCC3670 & Soil (wheat) & North Shoa & $09.80 / 38.73$ \\
\hline FCC4635 & Soil (Wheat) & Wollega & $09.50 / 35.50$ \\
\hline FCC 3727, FCC 3748 & Wheat stem & North Shoa & $08.66 / 38.21$ \\
\hline FCC4448 & Wheat stem & West Shoa & $08.98 / 37.85$ \\
\hline
\end{tabular}

${ }^{a}$ The crops in parentheses reflect those planted on the respective farms during the cropping season before the soil samples were collected in the subsequent off-season. The pulses were predominantly broad bean and peas, ${ }^{\mathrm{b}}$ Geographical positions (latitude/ longitude) and regions where the farms were located

in the dark at $25^{\circ} \mathrm{C}$ for $10-15$ days. Spore suspensions were prepared from these single-spore cultures and stored at $-80^{\circ} \mathrm{C}$ as glycerol $(15 \% v / v$, aqueous solution) stocks for later use. Forty-three of these isolates were morphologically identified as $F$. solani (Table 1) as described by Nelson et al. (1983).

A F. oxysporum f.sp. dianthi (CBS No. 491.97; Table 2) strain obtained from the Centraalbureau voor Schimmelcultures (CBS), Utrecht, The Netherlands, was included in the study as an outgroup taxon for phylogenetic analyses. All of the strains used in this study are maintained in the Fusarium Culture Collection (FCC) at the Forestry and Agricultural Biotechnology Institute (FABI), University of Pretoria, Pretoria, South Africa.
DNA extraction and sequencing

DNA was extracted from isolates using CTAB (N-cetyl$\mathrm{N}, \mathrm{N}, \mathrm{N}$-trimethyl-ammonium bromide) (Murray and Thompson 1980). Fragments of approximately 650 base pair (bp) and $290 \mathrm{bp}$ of the genes encoding Translation Elongation Factor $1 \alpha$ (TEF- $1 \alpha)$ and $\beta$ tubulin, respectively, were then amplified using PCR. For this purpose primer sets EF1/EF2 (O'Donnell et al. 1998) and 2A/2B (Glass and Donaldson 1995), and their respective reaction and cycling conditions were used. PCR products were purified using the QIAquick PCR purification kit (QIAGEN, Germany), and sequenced in both directions using the same primers as for the respective PCRs. The BigDye terminator 
Table 2 Strain information for the various TEF- $1 \alpha$ sequences obtained from GenBank and included in this study to represent known species and clades of the F. solani-H. haematococca complex

\begin{tabular}{|c|c|c|c|c|}
\hline Strain number & Species & MP & Origin & GenBank Acc. No. \\
\hline NRRL20438 & F. ambrosium & - & India & AF178332 \\
\hline NRRL31779a & F. brasiliense & - & Brazil & AY320150 \\
\hline NRRL31949a & F. cuneirostrum & - & Brazil & AY320161 \\
\hline NRRL22090 & F. illudens & - & New Zealand & AF178326 \\
\hline CBS No. 491.97 & F. oxysporum f. sp. dianthi & - & The Netherlands & DQ220144 \\
\hline NRRL31156 & F. phaseoli & - & USA & AY220187 \\
\hline NRRL22402 ${ }^{b}$ & F. solani f.sp. batatas & II & USA & AF178344 \\
\hline NRRL22142 ${ }^{b}$ & F. solani f.sp. cucurbitae & $\mathrm{V}$ & USA & AF178347 \\
\hline NRRL22153 ${ }^{\mathrm{b}}$ & F. solani f.sp. cucurbitae & I & - & AF178346 \\
\hline NRRL22157 ${ }^{\mathrm{b}}$ & F. solani f.sp. mori & III & Japan & AF178359 \\
\hline NRRL22570 & F. solani f.sp. piperis & - & Brazil & AF178360 \\
\hline NRRL22820 & F. solani f.sp. pisi & VI & USA & AF178355 \\
\hline NRRL22586 ${ }^{\mathrm{b}}$ & F. solani f.sp. robiniae & VII & USA & AF178353 \\
\hline NRRL22277 & F. solani f.sp. xanthoxyli & IV & Japan & AF178336 \\
\hline NRRL22098 & F. solani f.sp. cucurbitae & I & - & AF178327 \\
\hline NRRL22101 & F. striatum (homothallic) & - & Panama & AF178333 \\
\hline NRRL31950 a & F. tucumaniae & - & Brazil & AY320157 \\
\hline NRRL22823 ${ }^{\mathrm{c}}$ & F. virguliforme & - & USA & AF395647 \\
\hline NRRL22354 & Fusarium sp. & - & French Guiana & AF178338 \\
\hline NRRL22632 ${ }^{b}$ & Nectria plagianthi & - & New Zealand & AF178354 \\
\hline NRRL22389 & Nectria sp. (homothallic) & - & USA & AF178340 \\
\hline NRRL22436 ${ }^{\mathrm{d}}$ & Neocosmospora africana & - & South Africa & - \\
\hline NRRL22468 & Neocosmospora ornamentata & - & Guinea & - \\
\hline NRRL22166 & Neocosmospora vasinfecta & - & USA & AF178350 \\
\hline
\end{tabular}

${ }^{\mathrm{a}}$ (Aoki et al. 2005), ${ }^{\mathrm{b}}$ (O’Donnell 2000), ${ }^{\mathrm{c}}$ (Aoki et al. 2003), ${ }^{\mathrm{d}}$ Unpublished sequence kindly supplied by K. O’Donnell

sequencing kit (Version 3.1, Applied Biosystems, USA) and an ABI PRISM ${ }^{\mathrm{TM}} 3100$ DNA sequencer (Applied Biosystems) were used to obtain sequence data. All amplification and sequencing reactions were performed on a GeneAmp PCR System 9700 (Applied Biosystems).

Phylogenetic analyses

TEF-1 $\alpha$ sequences representing previously described species and clades (Clades 1-3) of the F. solani-H. haematococca complex (O’Donnell 2000; Aoki et al. 2003, 2005) were obtained from GenBank for inclusion in our analyses (Table 2). DNA sequences generated in this study have been deposited in GenBank under accession numbers DQ220207DQ220247 ( $\beta$-tubulin) and DQ220248-DQ220288 $(\mathrm{TEF}-1 \alpha)$. Nucleotide sequences were assembled using Sequence Navigator (Version 1.0.1, Applied Biosystems), and aligned using Multiple sequence Alignment based on Fast Fourier Transform (MAFFT,
Version 6, Katoh et al. 2002). Phylogenetic Analysis Using Parsimony (PAUP, Version 4.0b 10, Swofford 2002) was used to estimate parsimony-based phylogenetic relationships. For heuristic searches, 1,000 random additions of sequences and tree bisectionreconnection were used with branch swapping only on best trees. All characters were weighted equally and alignment gaps were treated as missing data. Bootstrap Proportions (BP; Hillis and Bull 1993) were estimated using 1,000 replications.

\section{AFLP analyses}

AFLP analysis was performed as described previously (Bogale et al. 2006), using EcoRI (E) and MseI (M) adaptor-specific primer sets E-AC/M-AG and E-TC/ M-AG (Inqaba Biotechnologies, RSA), each of which contained two selective nucleotides at their 3'-ends. Bands with similar migration patterns were considered identical, and the presence or absence of alleles at a particular locus was scored as one or 0 , respectively. 
Only bands that were between 100 and $500 \mathrm{bp}$ were considered; and rare alleles with a frequency of $<5 \%$, and ambiguous bands that were very intense or very faint, were excluded. Pair-wise distances among the isolates were calculated from the binary matrix using the simple mismatch coefficient (Sneath and Sokal 1973) recommended for dominant markers in haploid organisms (Kosman and Leonard 2005). The resulting distance matrices were used to cluster the isolates by the Unweighted Pair-Group Method using Arithmetic means (UPGMA) implemented in the Molecular Evolutionary Genetics Analysis (Version 2.1, Kumar et al. 2001). The goodness of fit of dendrograms and the respective distance matrices were determined using the cophenetic correlation analysis (Sneath and Sokal 1973).

\section{Results}

Phylogenetic analyses

Phylogenetic analysis was done with and without the 23 ingroup GenBank sequences (Table 2). The aligned TEF- $1 \alpha$ dataset in the presence of these 23 GenBank sequences contained 773 characters, of which 631 were parsimony uninformative, and thus excluded. Phylogenetic analysis using the remaining 142 informative characters separated the Ethiopian isolates and the taxa included from GenBank into three groups (Fig. 1). These groups corresponded with the three clades (Clades 1-3) previously characterised for the F. solani-H. haematococca species complex (O’Donnell 2000; Aoki et al. 2003, 2005). All of the Ethiopian isolates resided in Clade $3(\mathrm{BP}=98 \%)$. Within this clade, the Ethiopian isolates resolved into six well-supported lineages (Lineages 1-6) with FCC3815 as the only Ethiopian isolate residing in Lineage 6 . The aligned sequence data excluding the 23 GenBank sequences had 33 informative sites. Phylogenetic analysis based on these 23 informative sites for the 43 Ethiopian isolates and the outgroup taxon also recovered the six lineages although the bootstrap support for Lineage 6 was $<70 \%$ (Fig. 2a).

The aligned $\beta$-tubulin dataset contained 292 characters. Of these, only 12 were parsimony-informative, and did not allow full resolution of the taxa included (tree not shown). This dataset only resolved Lineage 5 of the Ethiopian F. solani isolates as distinct. However, inspection of the aligned sequences revealed the presence of three nucleotide sites that were fixed differentially (data not shown), separating the Ethiopian F. solani isolates into two distinct groups corresponding to the major AFLP Clusters A and B (see below, Fig. 2b). These polymorphisms were all situated at third codon positions within exons and resulted in synonymous substitutions.

\section{AFLP analyses}

A total of 65 distinctly polymorphic bands were scored for the 43 Ethiopian isolates included in this study. This dataset separated the Ethiopian F. solani isolates into two major clusters (Cluster A, 85\% BP; and Cluster B, 74\% BP) at a similarity of about $75 \%$ ( $\sim 25 \%$ dissimilarity, Fig. $2 b)$. The isolates in these clusters further resolved into six AFLP-based lineages although only Lineage 4 was well supported $(\mathrm{BP}=71 \%)$. These AFLP-based lineages corresponded to the six lineages that emerged from the TEF-1 $\alpha$ sequence data (Figs. 1 and 2). Cluster A contained Lineages 1 and 2, while Cluster B contained Lineages 3-6.

\section{Discussion}

In this study, we considered the phylogenetic diversity of $F$. solani isolates associated with agricultural soils and plant tissues from Ethiopia. The occurrence of Fusarium spp. in general and F. solani in particular, has not been well documented in Ethiopia or any other African country, except for South Africa (Fandohan et al. 2003). The only detailed account of Fusarium spp. in Ethiopia was made by Bekele and Karr (1997), where more than 19 different species were reported to be associated with head blight and other diseases of wheat. Bogale et al. (2006) reported that diverse members of the $F$. oxysporum species complex were associated with Ethiopian soils and plant tissues. We have shown here that both of these ecological niches in Ethiopia are also occupied by diverse $F$. solani isolates, the majority of which represent novel phylogenetic lineages in the $F$. solani-H. haematococca species complex. Our findings, together with those from the limited number of previous studies, therefore, suggest that agricultural environments in Ethiopia and other such under-explored African regions represent significant reservoirs of novel 
Fig. 1 One of 268 most parsimonious trees inferred from the TEF- $1 \alpha$ sequences of the Ethiopian isolates, as well as 23 GenBank sequences representing previously described species and clades (Clades 1-3; O'Donnell 2000) of the $F$. solani-H. haematococca species complex. These clades are indicated with thick lines. Fusarium oxysporum f.sp. dianthi (CBS No. 491.97) was used as an outgroup. Bootstrap values of $70 \%$ and higher are indicated above internodes. The tree scores were: length, 340; consistency index, 0.612 ; retention index, 0.818 ; rescaled consistency index, 0.500. Numbers following species names are NRRL numbers of strains, the TEF- $1 \alpha$ sequences of which we downloaded from GenBank (Table 2)

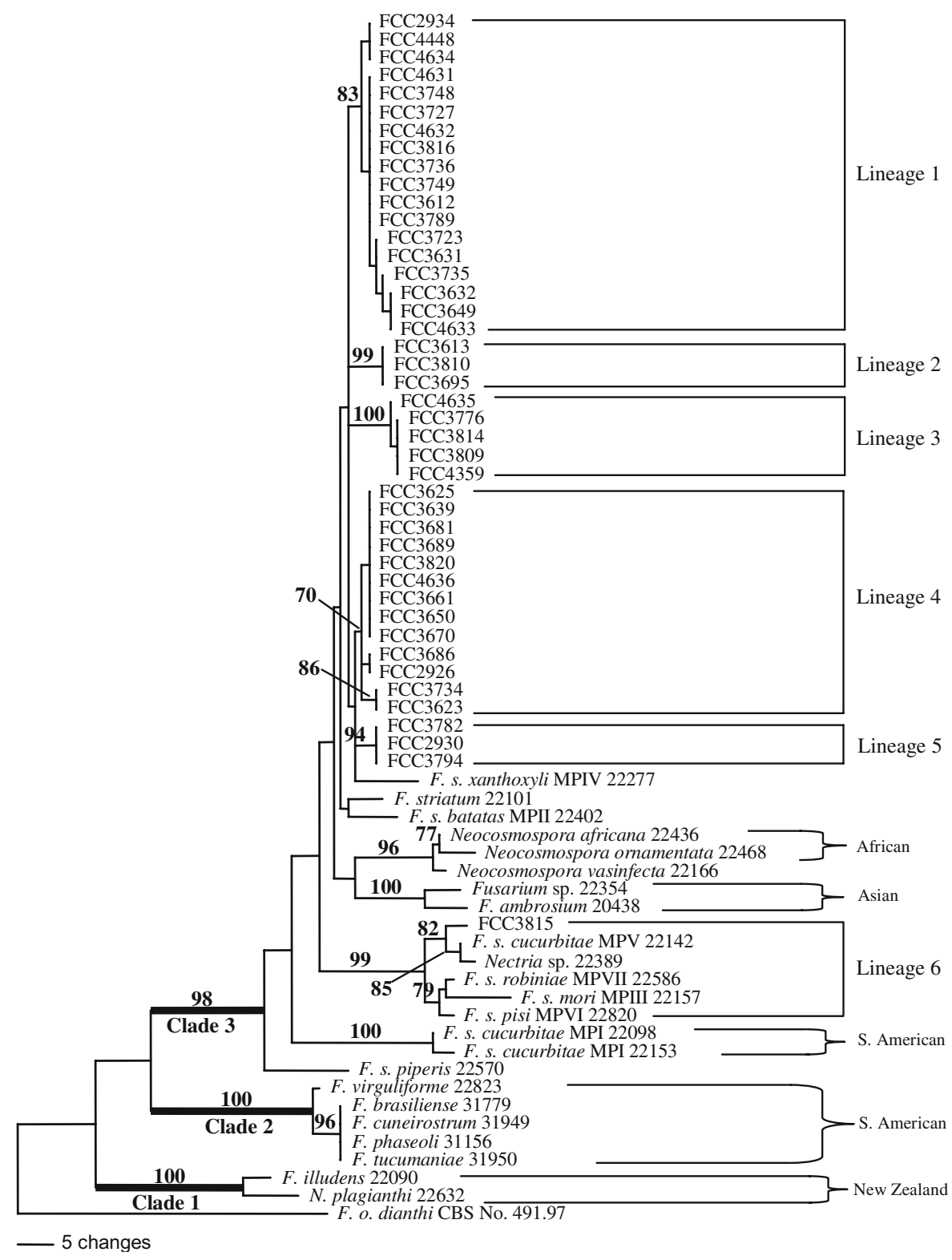

species and lineages of the genus Fusarium. A number of other fungal species have been shown to have higher diversity in native than in cultivated soils and plants (e.g., Edel et al. 1997; Gordon et al. 1992). This is mainly due to the higher diversity of the plant species in native soils, which supports more diverse species and strains of fungi. The diversity of $F$. solani in native soils and plants in Ethiopia may similarly be higher than that reported here for the sampled cultivated soils and plants.

The Ethiopian isolates of $F$. solani examined here appear to share a common ancestor with those from a variety of different plant hosts (Fig. 1). In the phylogenetic study of O'Donnell (2000), three major F. solani-H. haematococca clades (Clades 1-3) were identified. The hypothesis presented in that study was that vicariance associated with the fragmentation of Gondwanaland played a central part in shaping the evolutionary history of the fungi in this complex. Following this model, the complex arose near the New Zealand component of Gondwanaland because isolates collected in that region make up the most basal clade, Clade 1 (Fig. 1). Clade 2, consisting mainly of isolates collected in South America, and 
Clade 3, including isolates from Asia and Africa, are most likely to have emerged later because of the reproductive barrier imposed by fragmentation of the ancient southern hemisphere super continent. O'Donnell (2000) attributed the presence of non-gondwanan isolates (e.g., isolates collected in Africa and Asia, Fig. 1) in Clade 3 to distributions associated with agriculture. Consistent with this hypothesis, all of our Ethiopian $F$. solani isolates formed part of Clade 3. The isolates examined here, despite being associated with agricultural environments are, therefore, probably native to this region.

Analyses of TEF- $1 \alpha$ and AFLP data in this study separated the 43 Ethiopian $F$. solani isolates into six well-supported and concordant lineages (Figs. 1 and 2). AFLPs further grouped these lineages into two clusters
(Fig. 2b). Cluster A included Lineages 1 and 2, and Cluster B included Lineages 3-6. The separation of these clusters was also supported by the presence of $\beta$ tubulin nucleotide sites that were fixed differently for the two clusters. The fact that AFLP analysis samples the entire genome, as opposed to specific nuclear or mitochondrial regions in the case of gene genealogies (Vos et al. 1995; Majer et al. 1996), suggests that AFLP analyses provide independent measures of the evolutionary history of the organism. Consequently, phylogenies supported by the two techniques are likely to reliably reflect the evolutionary history of the F. solani isolates included in this study.

The biological significance of the distinct clusters and multiple phylogenetic lineages in Clade 3 is unclear (Figs. 1 and 2). None of the lineages or

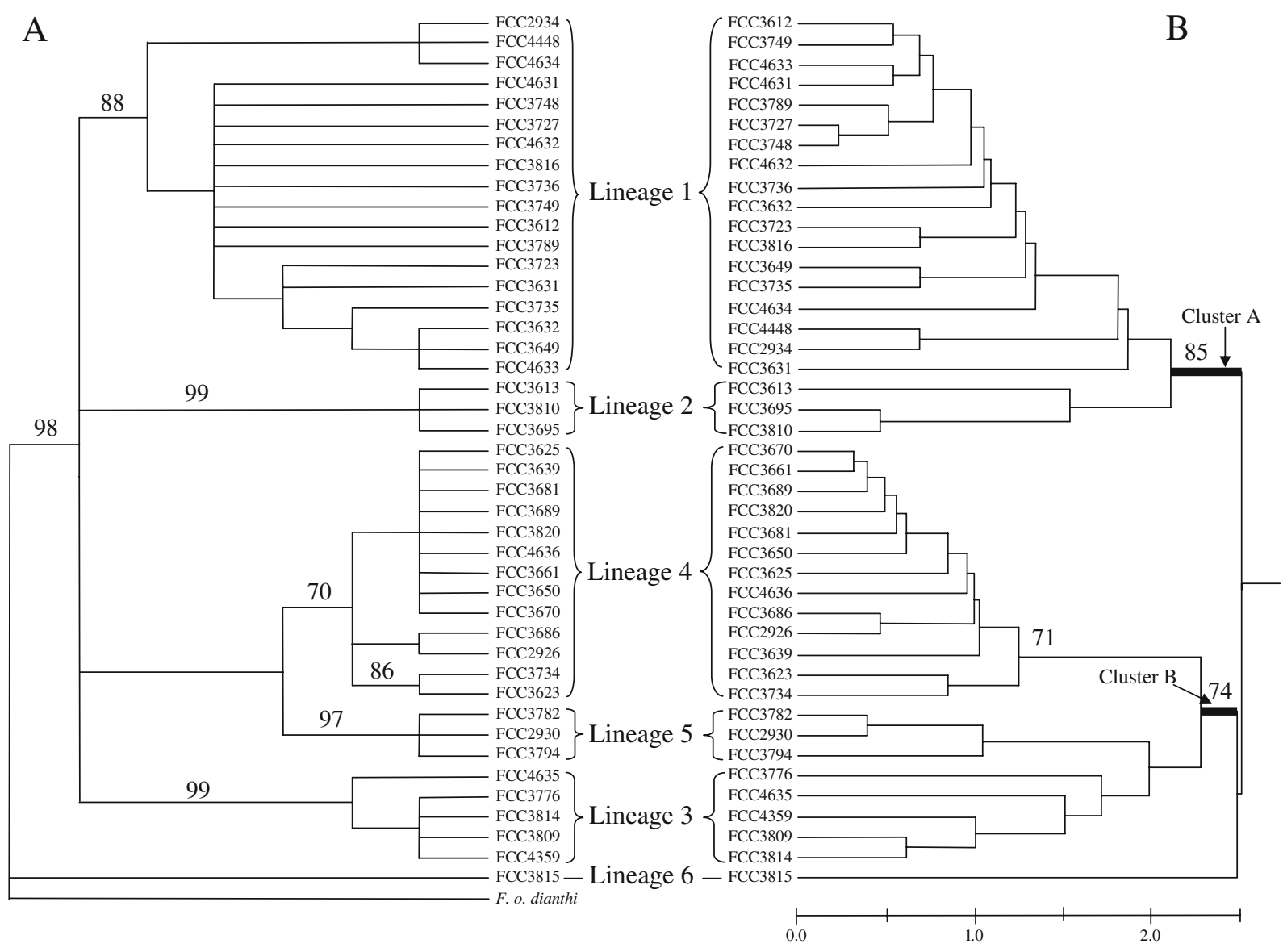

Fig. 2 TEF- $1 \alpha$ - and AFLP-based phylogeny of the 43 Ethiopian isolates. a A cladogram representing the 45 most parsimonious trees inferred from the TEF- $1 \alpha$ sequences using $F$. oxysporum dianthi as an outgroup. The tree scores were: length, 45; consistency index, 0.956; retention index, 0.986; and rescaled consistency index, 0.942 . Bootstrap values of $70 \%$ and higher are indicated above internodes. b UPGMA dendrogram generated from the AFLP data. The scale bar shows the percentage dissimilarity. Bootstrap values of $70 \%$ and higher are indicated above internodes. Thick lines lead to clusters 
clusters correlated to geographic origin or source (host or substrate) of isolates (Table 1; Figs. 1 and 2). The isolates also did not appear to form part of known lineages or species residing in this complex. The only exception was Lineage 6 (represented by FCC3815) that grouped with a homothallic isolate of Haematonectria sp. (NRRL22389) and an isolate of H. haematococca MP V (NRRL22142). Nevertheless, the fact that such lineages in species complexes, especially of Fusarium, potentially represent discrete species is increasingly recognised (e.g., O'Donnell et al. 1998, 2004). As a result, the morphology, pathology and ecology of a number of $F$. solani isolates have been re-examined and described as distinct taxa in the F. solani-H. haematococca complex (Aoki et al. 2003, 2005). Also, analyses of the reproductive mode of such novel lineages may reveal the presence of additional biological species in the complex. For example, Covert et al. (2007) recently showed that $F$. tucumaniae (previously also recognised as $F$. solani representing a distinct lineage in the complex) is heterothallic and capable of producing viable ascospores upon interaction between compatible individuals. Insight into the significance of the different lineages of $F$. solani reported here will, therefore, require a comprehensive sampling of native and agricultural soils, as well as extensive mating compatibility, pathogenicity and morphological studies.

Sequence information from the $\beta$-tubulin gene region was less informative than that from TEF- $1 \alpha$ for inference of phylogenetic relationships among isolates of the F. solani-H. haematococca complex. Contrary to the findings of O'Donnell (2000), we did not detect any divergent paralogues of this gene. Although our isolates probably also harbour such multiple copies of the $\beta$-tubulin gene, the PCR primers used in this study did not allow their detection. The primer set (May et al. 1987) used by O'Donnell (2000) and the primer set (Glass and Donaldson 1995) employed here, target different regions of the gene. The fact that we did not detect extra copies of the gene may, therefore, be because the region sequenced is highly conserved, thus limiting our ability to detect divergent nucleotide positions. It is also possible that the primer set used in this study amplified only some of the copies of the gene. Even so, our $\beta$-tubulin sequences harboured nucleotide sites diagnostic of the two AFLP clusters of Ethiopian isolates of the F. solani-H. haematococca complex.
The findings presented in this study contribute to the growing body of knowledge on the evolution and biology of fungi in the F. solani-H. haematococca complex. In terms of the evolution of this group of fungi, we support the view that $F$. solani isolates in Ethiopia and possibly the rest of Africa are potentially of gondwanan origin. In terms of biology and ecology, we have clearly highlighted some of the $F$. solani diversity associated with agricultural soils, stem samples of wheat and barley plants, and roots of banana plants collected from different locations in Ethiopia. We have further demonstrated that these $F$. solani isolates share complex phylogenetic relationships that are not easily interpretable in terms of geographic origin, host or substrate. Although their pathogenicity is unknown, studies on other Fusarium spp. have shown that pathogenic strains can arise from presumably non-pathogenic strains, and viceversa, through mutations involving only a few genes (Baayen et al. 2000). To fully understand the ecological significance of the $F$. solani isolates associated with the examined hosts and substrates, future studies should, therefore, also consider factors such as pathogenicity, distribution, and reproduction.

Acknowledgements This study was financially supported by the Tree Protection Co-operative Programme (TPCP) of FABI, University of Pretoria, South Africa; the National Research Foundation (NRF), South Africa; and the Agricultural Research and Training Programme (ARTP) of the Ethiopian Agricultural Research Organization (EARO), Ethiopia. We thank Dr. Kerry O'Donnell of the United States Department of Agriculture (USDA) for kindly supplying some of the TEF- $1 \alpha$ sequence information used in this study.

\section{References}

Aoki, T., O’Donnell, K., Homma, Y., \& Lattanzi, A. R. (2003). Sudden-death syndrome of soybean is caused by two morphologically and phylogenetically distinct species within the Fusarium solani species complex-F. virguliforme in North America and F. tucumaniae in South America. Mycologia, 95, 660-684. doi:10.2307/3761942.

Aoki, T., O'Donnell, K., \& Scandiani, M. M. (2005). Sudden death syndrome of soybean in South America is caused by four species of Fusarium: Fusarium brasiliense sp. nov., $F$. cuneirostrum sp. nov., $F$. tucumaniae and $F$. virguliforme. Mycoscience, 46, 162-183. doi:10.1007/s10267-005-0235-y.

Bayen, R. P., O’Donnell, K., Bonants, P. J. M., Cigelnik, E., Kroon, L. P. N. M., Roebroeck, E. J. A., \& Waalwijk, C. (2000). Gene genealogies and AFLP analyses in the 
Fusarium oxysporum complex identify monophyletic and non-monophyletic formae speciales causing wilt and rot diseases. Phytopathology, 90, 891-900. doi:10.1094/ PHYTO.2000.90.8.891.

Bekele, E., \& Karr, A. L. (1997). Fusarium head blight in Ethiopian wheat and the identification of species causing the disease. Pest Management Journal of Ethiopia, 1, 2936.

Bogale, M., Wingfield, B. D., Wingfield, M. J., \& Steenkamp, E. T. (2006). Characterization of Fusarium oxysporum isolates from Ethiopia using AFLP, SSR and DNA sequence analyses. Fungal Diversity, 23, 51-66.

Burgess, L. W., Summerell, B. A., Bullock, S., Gott, K. P., \& Backhouse, D. (1994). Laboratory manual for fusarium research (3rd ed.). Sydney: Fusarium Research Laboratory.

Covert, S. F., Aoki, T., O’Donnell, K., Starkey, D., Holliday, A., Geiser, D. M., et al. (2007). Sexual reproduction in the soybean sudden death syndrome pathogen Fusarium tucumaniae. Fungal Genetics and Biology, 44, 799-807. doi:10.1016/j.fgb.2006.12.009.

Edel, V., Steinberg, C., Gautheron, N., \& Alabouvette, C. (1997). Populations of nonpathogenic Fusarium oxysporum associated with roots of four plant species compared to soil borne populations. Phytopathology, 87, 693-697. doi:10.1094/ PHYTO.1997.87.7.693.

Fandohan, P., Hell, K., Marasas, W. F. O., \& Wingfield, M. J. (2003). Infection of maize by Fusarium species and contamination with fumonisins in Africa. African Journal of Biotechnology, 2, 570-579.

Glass, N. L., \& Donaldson, G. C. (1995). Development of primer sets designed for use with the PCR to amplify conserved genes from filamentous ascomycetes. Applied and Environmental Microbiology, 61, 1323-1330.

Godoy, P., Cano, J., Gené, J., Guarro, J., Höfling-Lima, A. L., \& Colombo, A. L. (2004). Genotyping of 44 isolates of Fusarium solani, the main agent of fungal keratitis in Brazil. Journal of Clinical Microbiology, 42, 4494-4497. doi:10.1128/JCM.42.10.4494-4497.2004.

Gordon, T. R., Okamoto, D., \& Milgroome, M. G. (1992). The structure and interrelationship of fungal populations in native and cultivated soils. Molecular Ecology, 1, 241249. doi:10.1111/j.1365-294X.1992.tb00183.x.

Hawthorne, B. T., Rees-George, J., \& Boradhurst, P. G. (1992). Mating behavior and pathogenicity of New Zealand isolates of Nectria haematococca (Fusarium solani). New Zealand Journal of Crop and Horticultural Science, 20, 51-57.

Hillis, D. M., \& Bull, J. J. (1993). An empirical test of bootstrapping as a method for assessing confidence in phylogenetic analyses. Systematic Biology, 42, 182-192. doi: $10.2307 / 2992540$.

Katoh, K., Misawa, K., Kuma, K., \& Miyata, T. (2002). MAFFT: A novel method for rapid Multiple sequence Alignment based on Fast Fourier Transform. Nucleic Acids Research, 30, 3059-3066. doi:10.1093/nar/ gkf436.

Kolattukudy, P. E., \& Gamble, D. L. (1995). Nectria haematococca. Pathogenesis and host specificity in plant diseases. Vol II Eukaryotes. In K. Kohmoto, U. S. Singh, \& R. P. Singh (Eds.), Pathogenesis and host specificity in plant pathogenic fungi and nematodes (pp. 83-102). UK: Pergamon.

Kosman, E., \& Leonard, J. (2005). Similarity coefficients for molecular markers in studies of genetic relationships between individuals for haploid, diploid, and polyploid species. Molecular Ecology, 14, 415-424. doi:10.1111/ j.1365-294X.2005.02416.x.

Kumar, S., Tamura, K., Jacobsen, I. B., \& Nei, M. (2001). MEGA 2: Molecular evolutionary genetics analysis software. Arizona: State University.

Leslie, J. F., \& Summerell, B. A. (2006). The Fusarium laboratory manual. Blackwell.

Li, D., Chung, K. R., Smith, D. A., \& Schardl, C. L. (1995). The Fusarium solani gene encoding kievitone hydratase, a secreted enzyme that catalyzes detoxification of a bean phytoalexin. Molecular Plant-Microbe Interactions, 8, 388-397.

Majer, D., Mithen, R., Lewis, B. G., Vos, P., \& Oliver, R. P. (1996). The use of AFLP fingerprinting for the detection of genetic variation in fungi. Mycological Research, 100, 1107-1111.

Matuo, T., \& Snyder, W. C. (1973). Use of morphology and mating populations in the identification of formae speciales in Fusarium solani. Phytopathology, 63, 562-565.

May, G. S., Tsang, M. L. -S., Smith, S., Fidel, S., \& Morris, N. R. (1987). Aspergillus nidulans $\beta$-tubulin genes are unusually divergent. Gene, 55, 231-243. doi:10.1016/0378-1119(87) 90283-6.

Murray, M. G., \& Thompson, W. F. (1980). Rapid isolation of high molecular weight plant DNA. Nucleic Acids Research, 8, 4321-4325. doi:10.1093/nar/8.19.4321.

Nash, S. M., \& Snyder, W. C. (1962). Quantitative estimations by plate counts of propagules of the bean root rot of Fusarium species in field soils. Phytopathology, 52, 567572.

Nelson, P. E., Toussoun, T. A., \& Marasas, W. F. O. (1983). Fusarium species: An illustrated manual of identification. University Park: Pennsylvania State University Press.

O'Donnell, K. (2000). Molecular phylogeny of the Nectria haematococca-Fusarium solani species complex. Mycologia, 92, 919-938. doi:10.2307/3761588.

O’Donnell, K., Kistler, H. C., Cigelnik, E., \& Ploetz, R. C. (1998). Multiple evolutionary origins of the fungus causing Panama disease of banana: Concordant evidence from nuclear and mitochondrial gene genealogies. Proceedings of the National Academy of Sciences of the United States of America, 95, 2044-2049. doi:10.1073/ pnas.95.5.2044.

O’Donnell, K., Ward, T. J., Geiser, D. M., Kistler, H. C., \& Aoki, T. (2004). Genealogical concordance between the mating type locus and seven other nuclear genes supports formal recognition of nine phylogenetically distinct species within the Fusarium graminearum clade. Fungal Genetics and Biology, 41, 600-623. doi:10.1016/j. fgb.2004.03.003.

Rossman, A. Y., Samuels, G. J., Rogerson, C. T., \& Lowen, R. (1999). Genera of Bionectriaceae, Hypocreaceae and Nectriaceae (Hypocreales, Ascomycetes). Studies in Mycology, $42,1-248$.

Sneath, P. A., \& Sokal, R. R. (1973). Numerical taxonomy. San Francisco: W.H. Freeman. 
Swofford, D. L. (2002). PAUP, Phylogenetic Analysis Using Parsimony version 4. Massachusetts: Sinauer Associates.

Toussoun, T. A., \& Snyder, W. C. (1961). The pathogenicity, distribution and control of two races of Fusarium (Hypomyces) solani f.sp. cucurbitae. Phytopathology, 51, $17-22$.

Van Etten, H. D. (1978). Identification of additional habitats of Nectria haematococca mating population VI. Phytopathology, 68, 1552-1556.

Van Etten, H. D., \& Kistler, H. C. (1988). Nectria haematococca, mating populations I and VI. Advances in Plant Pathology, 6, 189-206.
Vos, P., Hogers, R., Bleeker, M., Reijans, M., van de Lee, T., Hornes, M., et al. (1995). AFLP: A new technique for DNA fingerprinting. Nucleic Acids Research, 23, 44074414. doi:10.1093/nar/23.21.4407.

Windels, C. E. (1991). Current status of Fusarium taxonomy. Phytopathology, 81, 1048-1051.

Zhang, N., O'Donnell, K., Sutton, D. A., Nalim, F. A., Summerbell, R. C., Padhye, A. A., et al. (2006). Members of the Fusarium solani species complex that cause infections in both humans and plants are common in the environment. Journal of Clinical Microbiology, 44, 21862190. doi:10.1128/JCM.00 120-06. 